\title{
Educational Robotics for Inclusive Education
}

\author{
Linda Daniela ${ }^{1}$ (D) Miltiadis D. Lytras ${ }^{2,3}$
}

Published online: 17 December 2018

(c) Springer Nature B.V. 2018

\begin{abstract}
It has been quite a long time since S. Papert introduced the idea that children should be involved in the use of computers in the learning process to support the development of computational thinking. Nowadays, educational robotics is introduced in different dimensions of education, but mostly it is used as part of a compulsory educational process in nonformal educational activities, in activities to reduce the risks of early school leaving, and in initiatives introduced by some projects where different aspects of educational robotics are tested in activities with students who have diverse special needs. But till now robotics has mostly been associated with the field of Science, Technology, Engineering, and Mathematics, and outcomes of educational robotics are measured through the prism of improved knowledge in STEM subjects. In this special issue, journal researchers provide results on ER in the context of inclusive education.
\end{abstract}

Keywords Educational robotics · Inclusive education $\cdot$ Special needs $\cdot$ Socio-economic status $\cdot$ Cultural diversity $\cdot$ Gender differences

\section{Expanding Role of Educational Robotics}

The robotization of different fields is not a new process, and the first researcher who started to talk about the possibility of using robots for educational purposes was Papert (1984), who developed the idea that students construct their knowledge in math and understand the basic principles of physics if there are computers used in the learning process, where they are active participants in programming. Later on, he developed the programming language LOGO and Turtle robots to allow students to participate in the construction process and to discover the knowledge by themselves. He defined his idea as constructionism, which was widely developed and used in educational settings. It is not a new concept for education, although educational robotics (ER) is mostly associated with Science, Technology, Engineering, and Mathematics (STEM) in developing the understanding of mathematical concepts and principles of physics (Williams et al. 2007), engineering (Ariza et al. 2017;

Linda Daniela

linda.daniela@lu.lv

1 University of Latvia, Riga, Latvia

2 School of Business, Deree College, The American College of Greece, 153-42 Athens, Greece

3 Effat College of Engineering, Effat University, P.O. Box 34689, Jeddah, Saudi Arabia 
Zaldivar et al. 2013), and other branches of STEM (Witherspoon et al. 2018; Eck et al. 2014) and in developing multiskills and knowledge in different levels of education from preschool to higher education. Lately, new research directions have been developed where it is proved that ER has such positive side effects as improved learning motivation (Daniela and Strods 2016, 2018; Daniela et al. 2017; Alimisis 2014), improved interest in learning itself, possibilities of using ER with special needs students to involve them in active learning processes, overcoming the gender gap in STEM education, and other factors that can lead to risks of social marginalization and then to risks of early school leaving.

This special issue is devoted to researches on possibilities of using ER in the context of inclusive education. It provides a conceptual framework for possibilities and challenges of ER in inclusive education.

It is imperative to analyse ER in the scaffolding of learning outcomes, which the editors propose to divide into three domains: (a) development of knowledge, which can be analysed from a knowledge building, knowledge construction, or knowledge development perspective; (b) attitude to learning and intercorrelations among attitude, motivation, and learning success; (c) and students' well-being, which depends on environmental aspects such as an accessible and welcoming environment, attitude to students, acceptance, support, students' feeling of self-confidence, and students' self-perception.

\section{The Role of Educational Robotics for Inclusive Education}

There are two approaches to inclusive education, which do not exclude each other but only concern the extent to which inclusive education is understood. One is where inclusive education is understood as education where support is provided to students with different special needs, understanding special needs as disabilities. As mentioned in the Dakar Framework for Action 2000 (World Education Forum 2000), all children and youth must have the opportunity to learn. Since then, many other political documents have been developed, and countries have agreed on them. In some countries, inclusive education is understood as education where children with special needs are supported to give them equal opportunities (Xu et al. 2018; Liasidou 2012; Burke and Sutherland 2004).

Another approach is wider, where inclusive education is understood as occurring where support is provided for both students with special needs and students with different cultural backgrounds, different socioeconomic statuses, gender differences, and so on, as defined in UNESCO's Policy Guidelines on Inclusion for Education (2009), which is defined as socially fair by other authors (Waitoller and Artiles 2013; Thomas 2013).

The editors believe that ER is best analysed through the wider prism as it is defined in the Salamanca Declaration, which is signed by 92 countries (UNESCO 1994), despite the fact that the declaration was then adopted to support children with special needs. The editors would like to define four dimensions of inclusive education, where problems can arise that can lead to social exclusion. This can occur on diverse levels: exclusion from education systems or from particular fields of education, such as technology. The editors have developed the conceptual model of inclusive education and educational robotics (see Graph 1). These four dimensions are:

- Special needs, as one of the major risk factors that can both reduce access to education in general and limit access to learning in particular areas. As special needs, this article understands any disability, without going into details of each specific diagnosis, as well 


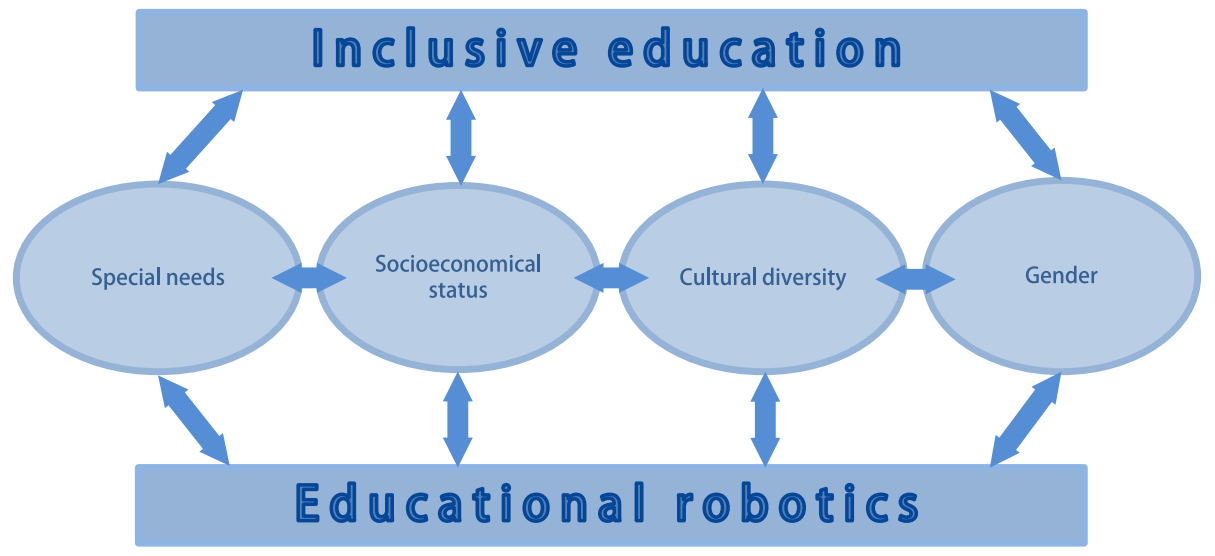

Graph 1 Concept of interrelations among inclusive education and educational robotics (prepared by authors)

as other special needs that may not be so obvious. For example, children who have colour discoloration problems can be confronted with the programming of LEGO robots with a high emphasis on colours; therefore, in the context of inclusive education, not only diagnosed and apparent disabilities but also all special needs that can affect learning should be met.

- Socioeconomic status (SES), which can influence access to education. There can be hidden aspects as well, where access to education is formally provided but includes only the possibility to learn. Learning materials, support materials, and the possibility of participating in nonformal activities should be financed by the student's family. In countries where the quality of education differs in public and private educational institutions, access to education is provided, but quality of education still is an actor that plays the significant role. There are countries where compulsory education is free of charge, but higher levels of education and nonformal education are not free of charge, and this means that they are not accessible for everyone. If ER is not used in compulsory education, then families with low SES will not have the possibility to provide these innovative learning activities for their children, and this means that the positive outcomes from educational robotics are unavailable for these students.

- Cultural diversity. In this dimension can be included children of nomadic families, first-generation migrant families, Roma children, Muslim girls, and so forth. Religious beliefs about innovation, about the involvement of girls in science, and so on can play an important role.

- Gender balance, where equal opportunities should be provided for all. In some countries, access to education for girls is still a problem, and in some countries research results show that learning outcomes in particular fields are higher for girls than for boys (for example, reading literacy). Also, obstacles exist that lead to gender imbalances in different fields, such as where educational sciences become more predominantly female and Information Communication Technologies (ICT) remains predominantly field of male.

It is important to understand that these dimensions are not separated from one another; for example, a student might be a girl with special needs from a migrant family that has a low 
socioeconomic background, and this can make the barriers even higher. The dimensions of inclusive education defined in this conceptual model have only illustrative purposes, and other dimensions can be added as well. This model only shows possible barriers to education and particularly to educational robotics.

In the planning and organization of innovative activities, it is imperative to remember that it is not acceptable to reduce access to education for anyone while providing special support for some group of students, and that the 'labelling' of students is also unacceptable. For example, while providing special support for students from families with a lower socioeconomic level, it is not acceptable to indicate that these activities are intended for a special ('labelled') group. The focus of inclusive education is to provide opportunities for everyone and not to create new marginalizations. In assessing the reach of educational objectives, it is necessary to use some structure-for example, logic model principles, where actors are indicated and all are evaluated through the prism of inclusive education (Calder Stegemann and Jaciw 2018). In analysing the outcomes of ER, it is important to indicate and evaluate all the possible outcomes of the inclusive learning process, such as knowledge, attitudes, and well-being, not focusing on only one dimension of possible outcomes in knowledge domain (see Graph 2).

Educational robotics can serve as a tool for knowledge construction and as an assistive tool for students who have problems in specific fields, or ER may be used to change students' attitudes to learning - class culture - allowing everyone to be accepted and involved. While analysing the outcomes of such a process, it is acceptable that educational robotics have not

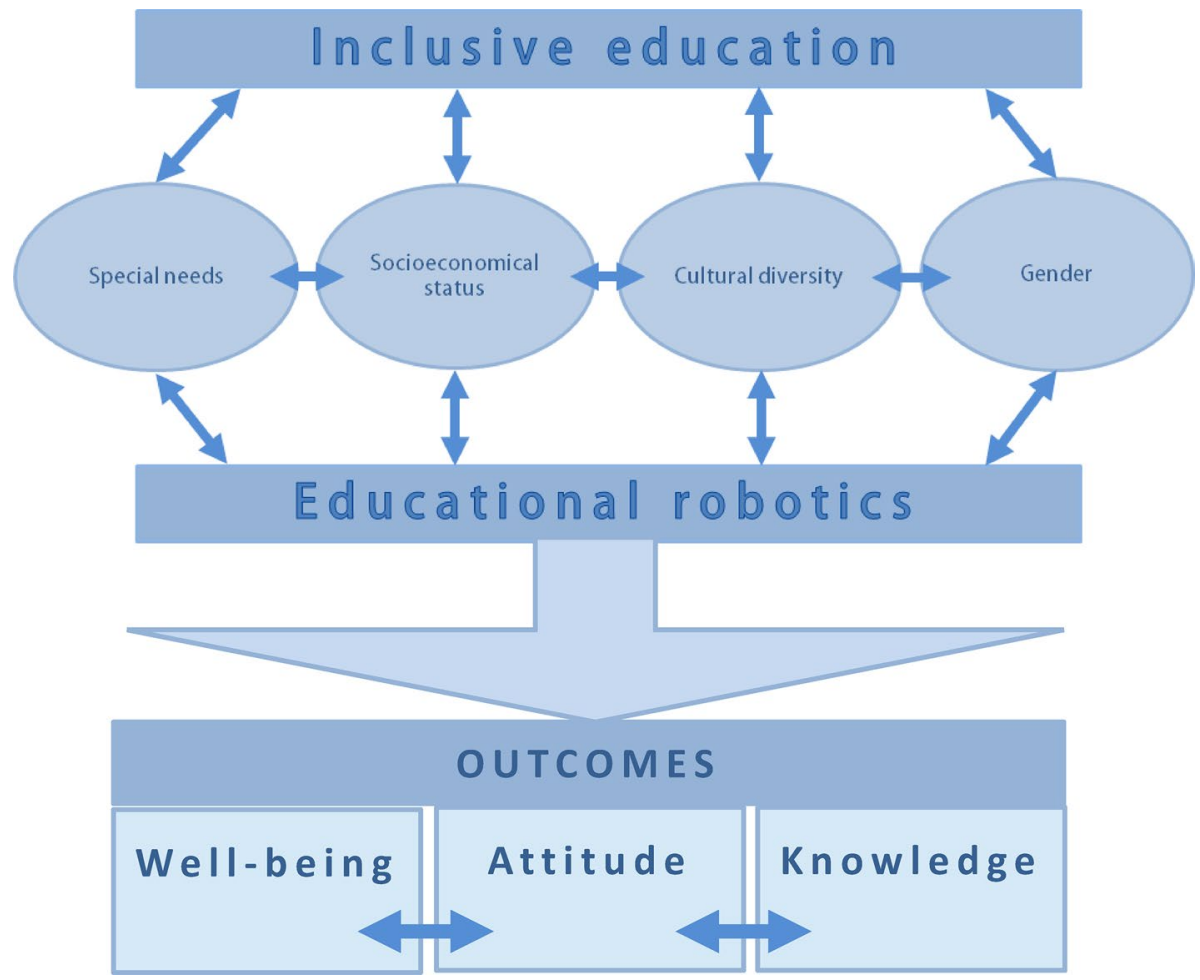

Graph 2 Conceptual model of outcomes of ER use (prepared by authors) 
provided much impact on knowledge improvement, but ER can play an important role in another aspects that are important for keeping students engaged and motivated. This, in turn, reduces the risks of social exclusion and dropping out (Daniela and Strods 2018; Alimisis 2014; Moro et al. 2018; Karkazis et al. 2018; Karampinis 2018), hence providing inclusive education for everyone.

Educational robotics also shouldn't be taken as providing a panacea for all the problems that exist in education. However, an important principle of inclusive education is 'no child left behind', and everyone should remember the principles of zone of proximal development (Vygotski 1978), principles of motivation (Bandura 1997; Migdley and Urdan 2001), and previous knowledge. On one hand, educational robotics is a tool to support reaching outcomes (improved knowledge, attitude and well-being), but on the other hand it also brings challenges that can cause opposite effects when "avoidance" motivation (Migdley and Urdan 2001) is developed, if the task is too complicated and pedagogical support is not provided. Another challenge is the assumption that ER supports knowledge building, forgetting about other possible outcomes that play an important role in helping students to become active learning actors. Also, challenges can be raised if ER activities are provided as nonformal educational activities that are available for a special group of students- those whose families can pay for these activities or those who are labelled as the focus group of activities (for example, 'children at risk', 'Muslim girls', etc.). Children don't want to be labelled. If ER activities are provided at a time when the school bus can't take students home, this again provides the possibility to participate for those who live close to the educational setting or whose families can take them home by car. Also, students who are labelled can feel satisfied and encouraged inside such groups, but they can feel excluded from the compulsory education environment because of feeling 'labelled'. This risk can be observed not only in countries of low gross private domestic investment (GPDI), where formally the possibility is provided, but hidden factors are not met.

Inclusive education can't be perceived as the lattice, which people accept without seeing what is behind it - the hidden factors. It is not acceptable when educators start activities that are supposed to be inclusive, but the hidden factors are not all evaluated. For example, if educators decide to organize ER activities with a student who has cerebral palsy, it is not acceptable not to consider how much stress these activities could cause for this student (for example, will the student be able to operate with tiny details?). Or if educators decide to organize group activities for a child with an autistic spectrum disorder, it is not acceptable not to consider that, maybe for this student, participation in group activities can cause extreme stress and that such activities may keep the student under stress for a while, blocking the possibility to learn something new. All these examples are given to illustrate that ER should be analysed multidimensionally, taking into account not only well-known problems but also all the hidden aspects. Otherwise, inclusiveness may be only a fake inclusiveness, and it may not support knowledge construction, change of attitude to learning, and students' well-being.

The papers published in this special issue reveal a small part of the possible research directions in the field of ER-specifically, ER for inclusive education-but they provide a good background for developing further research directions and grounds for new dimensions of smart pedagogy (Daniela 2018).

\section{References}

Alimisis, D. (2014). Educational robotics in teacher education: An innovative tool for promoting quality education. In L. Daniela, I. Lūka, L. Rutka, \& I. Žogla (Eds.), Teacher of the 21st century: Quality 
education for quality teaching (pp. 28-39). Newcastle upon Tyne: Cambridge Scholars Publishing. ISBN 978-1-4438-5612-6.

Ariza, D. V., Palacio, A. M., Aragón, I. P., Pulido, C. M., Logreira, E. A., \& McKinley, J. R. (2017). Application of color sensor programming with LEGO-Mindstorms NXT 2.0 to recreate a simplistic plague detection scenario. Scientia et Technica, 22(3), 268-272.

Bandura, A. (1997). Self-efficacy: The exercise of control. New York: Freeman.

Burke, K., \& Sutherland, C. (2004). Attitudes towards inclusion: Knowledge vs. experience. Education, $125(2), 163-172$.

Calder Stegemann, K., \& Jaciw, A. P. (2018). Making it logical: Implementation of inclusive education using a logic model framework. Learning Disabilities: A Contemporary Journal, 16(1), 3-18.

Daniela, L. (2018). Smart pedagogy for technology enhanced learning. In L. Daniela (Ed.), Didactics of smart pedagogy: Smart pedagogy for technology enhanced learning (pp. 1-20). Cham: Springer. ISBN 978-3-030-01550-3.

Daniela, L., \& Strods, R. (2016). The role of robotics in promoting the learning motivation to decrease the early school leaving risks. In Presented at the ROBOESL conference, Athens: Proceedings Athens. Retrieved September 15, 2018 from http://roboesl.eu/conference/?page_id=508.

Daniela, L., \& Strods, R. (2018). Robot as agent in reducing risks of early school leaving. In L. Daniela (Ed.), Innovations, technologies and research in education (pp. 140-158). Newcastle upon Tyne: Cambridge Scholars Publishing. ISBN 1-5275-0622-3.

Daniela, L., Strods, R., \& Alimisis, D. (2017). Analysis of robotics-based learning for preventing school failure and early school leaving in gender context. In EDULEARN17 proceedings (pp. 810-818). Presented at the 9th international conference on education and new learning technologies, Barcelona: IATED. ISBN 9788469737774 . ISSN 2340-1117.

Eck, J., Hirschmugl-Gaisch, S., Kandlhofer, M., \& Steinbauer, G. (2014). A cross-generational robotics project day: Pre-school children, pupils and grandparents learn together. Journal of Automation, Mobile Robotics and Intelligent Systems, 8(1), 12-19. https://doi.org/10.14313/JAMRIS_1-2014/2.

Karampinis, T. (2018). Activities and experiences through RoboESL project opportunities. International Journal of Smart Education and Urban Society, 9(1), 13-24. https://doi.org/10.4018/IJSEUS.

Karkazis, P., Balourdos, P., Pitsiakos, G., Asimakopoulos, K., Saranteas, I., Spiliou, T., et al. (2018). To water or not to water: The Arduino approach for the irrigation of a field. International Journal of Smart Education and Urban Society, 9(1), 25-36. https://doi.org/10.4018/IJSEUS.

Liasidou, A. (2012). Inclusive education and critical pedagogy at the intersections of disability, race, gender and class. Journal for Critical Education Policy Studies, 10, 168-184.

Migdley, C., \& Urdan, T. (2001). Academic self-handicapping and performance goals: A further examination. Contemporary Educational Psychology, 26, 61-75.

Moro, M., Agatolio, F., \& Menegatti, E. (2018). The development of robotic enhanced curricula for the RoboESL project: Overall evaluation and expected outcomes. International Journal of Smart Education and Urban Society, 9(1), 48-60. https://doi.org/10.4018/IJSEUS.

Papert, S. (1984). New theories for new learnings. School Psychology Review, 13(4), 422-428.

Thomas, G. (2013). A review of thinking and research about inclusive education policy, with suggestions for a new kind of inclusive thinking. British Educational Research Journal, 39(3), 473-490.

UNESCO. (1994). The UNESCO Salamanca statement. Retrieved September 15, 2018 from http://www. unesco.org/education/pdf/SALAMA_E.PDF.

UNESCO. (2009). Policy guidelines on inclusion for education. http://unesdoc.unesco.org/image s/0017/001778/177849e.pdf.

Vygotski, L. S. (1978). Interaction between learning and development. In M. Cole, V. John-Steiner, S. Scribner, \& E. Souberman (Eds.), Mind and society (pp. 79-91). Cambridge: Harvard University Press.

Waitoller, F., \& Artiles, A. J. (2013). A decade of professional development research for inclusive education: A literature review and notes for a sociocultural research program. Review of Educational Research, 83, 319-356.

Williams, D. C., Yuxin, M., Prejean, L., Ford, M. J., \& Lai, G. (2007). Acquisition of physics content knowledge and scientific inquiry skills in a robotics summer camp. Journal of Research on Technology in Education, 40(2), 201-216.

Witherspoon, E. B., Schunn, C. D., Higashi, R. M., \& Shoop, R. (2018). Attending to structural programming features predicts differences in learning and motivation. Journal of Computer Assisted Learning, 34(2), 115-128. https://doi.org/10.1111/jcal.12219.

World Education Forum. (2000). The Dakar framework for action. Education for all: Meeting our collective commitment. Dakar: World Education Forum. 
Xu, S. Q., Cooper, P., \& Sin, K. (2018). The 'learning in regular classrooms' initiative for inclusive education in China. International Journal of Inclusive Education, 22(1), 54-73.

Zaldivar, D., Cuevas, E., Pérez-Cisneros, M. A., Sossa, J. H., Rodríguez, J. G., \& Palafox, E. O. (2013). An educational fuzzy-based control platform using LEGO robots. International Journal of Electrical Engineering Education, 50(2), 157-171. https://doi.org/10.7227/IJEEE.50.2.5.

Publisher's Note Springer Nature remains neutral with regard to jurisdictional claims in published maps and institutional affiliations. 